\section{Resistance to Gummy Stem Blight in Muskmelon}

\author{
D.J. McGrath, L. Vawdrey, and I.O. Walker \\ Department of Primary Industries, Bowen Horticultural Research Station, \\ P.O. Box 538, Bowen, Queensland 4805, Australia
}

Additional index words. Cucumis melo, Didymella hryoniae, disease resistance

Abstract. Resistance to gummy stem blight [Didymella bryoniae (Auersw.) Rehm] was evaluated in two accessions of Cucumis melo L., PI 266935 and PI 266934. Based on disease reaction scores and dry weights, PI 266934 possessed much greater resistance than PI 266935. The quality of resistance of PI 266934 was unaffected by the ranges of seedling ages and inoculum concentrations used. No melon cultivar, to our knowledge, is highly resistant to gummy stem blight in the field, and alternative sources of superior resistance are potentially useful for breeding.

Gummy stem blight (GSB) of muskmelon, caused by Didymella bryoniae, is a significant disease in all areas of extensive melon production in Australia. Annual production losses in the Riverland district of New South Wales are $\approx 30 \%$ of early season melons (J. Salvestrin, personalcommunication). In Queensland, disease severity in coastal production centers varies with rainfall, and may result in extensive crop losses. Higher incidence of GSB in the last decade is attributed to the widespread use of plastic mulch and trickle irrigation, which maintain a favorable microclimate for pathogen development (N. Meurant, personal communication).

Adequate control of GSB through fungicide applications is difficult during periods of

Received for publication 4 May 1992. Accepted for publication 25 Mar. 1993. The cost of publishing this paper was defrayed in part by the payment of page charges. Under postal regulations, this paper therefore must be hereby marked advertisement solely to indicate this fact. high humidity and rainfall, and under these conditions genetic resistance is a better alternative. Sowell et al. (1966) identified resistance to GSB in PI 140471, from which three cultivars with resistance were developed (Norton 1971, 1972; Norton et al., 1985). A dominant gene, $M C$, in PI 140471 confers resistance to GSB (Prasad and Norton, 1967). The resistance in PI 140471, however, was inadequate during severe disease epidemics (Sowell, 1981). Two additional lines with resistance, PI 266935 and PI 436533, were identified in glasshouse and field tests (Sowell, 1981). Although the resistance of these two lines was similar to that of PI 140471, they provided a diversity of resistant germplasm for plant breeders to exploit.

Currently, to our knowledge, no melon cultivar is sufficiently resistant to GSB in the field, and alternative sources of resistance would be potentially useful. In this paper, we report a previously unidentified genotype with seedling resistance superior to PI 266935. We also discuss the effect of seedling age and inoculum concentration on this resistance, and suggest a method for selecting plants with resistance from breeding populations.

Inoculum preparation. Isolates of Didymella bryoniae were acquired by excising small sections of crown lesions and plating on potato dextrose agar (PDA) containing 50 mg streptomycin sulfate/liter (S/PDA). Singlespore isolations were made, and cultures were freeze-dried. One single-spore culture, BRIP 3459 , was used throughout these experiments. It had typical cultural characteristics, including development of all symptoms in inoculated melon plants. Spores were washed from 14-day-old cultures grown on S/PDA using sterile distilled water, and concentration was quantified with a hemocytometer.

Plant culture and inoculation. Seedlings were grown in 1 peat : 1 vermiculite mix $(v / v)$, where they were inoculated by spraying both leaf surfaces with an atomized spore suspension. Following inoculation, seedlings were transplanted to $18-\mathrm{cm}$ (2.3-liter) pots, three per pot, containing 1 peat : 1 sand $(\mathrm{v} / \mathrm{v})$ mix. Seedlings of inoculated and noninoculated (control) treatments were incubated for 4 days in a moist, $27 \pm 2 \mathrm{C}$ chamber, then transferred to open benches in a greenhouse. Each pot represented an experimental unit.

Disease assessment. Foliar symptoms were

Table 1. Ratings of foliar disease severity on seedlings of two ages for four melon cultigens inoculated with $1 \times 10^{6}$ spores of Didymella bryoniael $\mathrm{ml}$.

\begin{tabular}{|c|c|c|}
\hline \multirow[b]{2}{*}{ Cultigen } & \multicolumn{2}{|c|}{ Seedling age (days) at inoculation } \\
\hline & 29 & 44 \\
\hline \multicolumn{3}{|c|}{ Disease severity rating ${ }^{2}$} \\
\hline Laguna & 5.0 & 4.8 \\
\hline Planters Jumbo & 1.2 & 1.0 \\
\hline PI 266935 & 1.5 & 0.7 \\
\hline PI 266934 & 0.3 & 0.3 \\
\hline $\operatorname{LSD}_{0.05}{ }^{y}$ & & \\
\hline
\end{tabular}

${ }^{2}$ Disease ratings were from 0 (no visible necrosis) to 5 ( $>80 \%$ leaf area necrosis).

'Least significant difference for $P \leq 0.05$. 
Table 2. Dry weight per seedling of two ages for four melon cultigens inoculated with $1 \times 10^{6}$ spores of Didymella bryoniae/ml.

\begin{tabular}{|c|c|c|c|c|c|}
\hline \multirow[b]{3}{*}{ Cultigen } & \multicolumn{5}{|c|}{ Seedling age (days) } \\
\hline & \multicolumn{2}{|c|}{29} & & \multicolumn{2}{|c|}{44} \\
\hline & Inoculated & Control & & Inoculated & Control \\
\hline \multicolumn{6}{|c|}{ Dry wt $(g) /$ seedling } \\
\hline Laguna & 0.35 & 0.57 & & 0.60 & 0.85 \\
\hline Planters Jumbo & 0.66 & 0.66 & & 0.60 & 0.79 \\
\hline PI 266935 & 0.50 & 0.65 & & 0.64 & 0.88 \\
\hline PI 266934 & 0.17 & 0.29 & & 0.56 & 0.52 \\
\hline $\mathrm{LSD}_{0.05}{ }^{\mathrm{T}}$ & & & 0.15 & & \\
\hline
\end{tabular}

${ }^{2}$ Least significant difference for $P \leq 0.05$.

recorded for each seedling, using an index of necrotic tissue on the following 0 to 5 scale: 0 ) no infection visible; 1$)>0 \% \leq 20 \%$ leaf area necrotic; 2) $>20 \% \leq 40 \%$ leaf area necrotic; 3 ) $>40 \% \leq 60 \%$ leaf area necrotic; 4) $>60 \% \leq 80 \%$ leaf area necrotic; 5) $>80 \%$ leaf area necrotic.

Effects of genotype, seedling age, and inoculum concentration. Two experiments were completed. One experiment compared four genotypes (Laguna, Planters Jumbo, PI 266935, and PI 266934). Seedlings were inoculated at each of two ages (29 and 44 days after sowing). Inoculum was applied at a concentration of $1 \times 10^{6}$ spores $/ \mathrm{ml}$. Disease severity was rated 6 days after inoculation, and seedlings were cut at the cotyledonary node to determine oven dry weights 7 days after inoculation.

The second experiment compared disease severity levels on two genotypes (Laguna and PI 266934) using three inoculum concentrations $\left(0,1 \times 10^{5}\right.$, and $1 \times 10^{6}$ spores $\left./ \mathrm{ml}\right)$ and four seedling ages $(11,17,25$, and 32 days after sowing). Disease severity was rated, and seedlings were cut for dry-weight determinations 15 days after inoculation.

All treatments in both experiments were arranged in factorial combination in randomized block designs. There were two and four replications in the first and second experiments, respectively.

No disease developed on noninoculated seedlings of any genotype in either experi- ment. The severity of visible necrosis on inoculated plants differed significantly among genotypes. PI 266934 seedlings were significantly less diseased than all others at each of two seedling ages (Table 1). Similarly, inoculated seedlings of all genotypes, except PI 266934, weighed significantly less than their noninoculated controls at age 44 days. This was also true for seedlings at 29 days, except Planters Jumbo (Table 2). Inoculated PI 266934 seedlings were not significantly different from their noninoculated controls.

Inoculated Laguna seedlings developed less disease when 32 days old than when 11 days old, and when inoculum concentration was low $\left(1 \times 10^{5}\right.$ spores $\left./ \mathrm{ml}\right)$ rather than high, except at 11 days (Table 3). No significant disease developed on any inoculated PI 266934 plants. All inoculated Laguna seedlings weighedless than their controls, and seedlings inoculated with the high concentration weighed less than those treated with the low (Table 4), except at 32 days. Following inoculation, PI 266934 seedlings weighed less than their controls at 17 and 32 days, but not at 25 and 11 days. Weights of PI 266934 seedlings were similar for high and low inoculum concentrations.

The results confirmed the resistance of PI 266935 reported by Sowell (1981). However, foliar disease ratings of PI 266934 were significantly less than those for PI 266935 for both seedling ages (Table 1). Reductions in dry weight following inoculation were significant for PI 266935, but not for PI 266934 (Table 2). These data suggest that the resistance of PI 266934 was conditioned by a different mechanism than that of PI 266935. The high resistance level to GSB in PI 266934 should be useful for breeding. Work is required to clarify the inheritance of this resistance and its relationship to previously identified genes (Prasad and Norton, 1967).

In general, this study revealed that PI 266934 maintained similar or marginally smaller dry weight after inoculation, whereas the other cultigens were substantially smaller. Although disease scores would be the primary selection criterion for resistance in a breeding population, dry-weight comparisons for a small number of lines could be a refinement that would enhance the efficiency of progeny testing. The expression of resistance would probably be modified by the choice of recurrent parent and the inheritance of resistance, but it is likely that resistant progenies would be distinguished by performance similar to that reported-here.

\section{Literature Cited}

Norton, J.D. 1971. Gulfcoast-A sweet cantaloupe for the produce chain store market. Alabama Agr. Expt. Sta. Lflt. 82.

Norton, J.D. 1972. Chilton-A high quality fruit for the commercial market. Alabama Agr. Expt. Sta. Lflt. 84.

Norton, J.D., R.D. Cosper, D.A. Smith, and K.S. Rymal. 1985. Aurora-A high quality disease resistant cantaloupe. Alabama Agr. Expt. Sta. Circ. 278

Prasad, K. and J.D. Norton. 1967. Inheritance of resistance to Mycosphaerella citrullina in muskmelon. Proc. Amer. Soc. Hort. Sci. 91:396-400.

Sowell, G., Jr. 1981. Additional sources of resistance to gummy stem blight of muskmelon. Plant Dis. 65:253-254.

Sowell, G., Jr., K. Prasad, and J.D. Norton. 1966. Resistance of Cucumis melo introductions to Mycosphaerella citrullina. Plant Dis. Rptr. 50:661-663.

Table 3. Ratings of foliar disease severity on seedlings of four ages for two melon cultigens inoclated with two concentrations of Didymella bryoniae.

\begin{tabular}{|c|c|c|c|c|c|c|c|c|}
\hline \multirow{3}{*}{$\begin{array}{l}\text { Inoculum } \\
\text { concn } \\
\text { (spores/ml) }\end{array}$} & \multicolumn{8}{|c|}{ Seedling age (days) at inoculation } \\
\hline & \multicolumn{2}{|c|}{$\overline{11}$} & \multicolumn{2}{|c|}{17} & \multicolumn{2}{|c|}{25} & \multicolumn{2}{|c|}{32} \\
\hline & Laguna & PI 266934 & Laguna & PI 266934 & Laguna & PI $26 \overline{2634}$ & Laguna & PI 266934 \\
\hline \multicolumn{9}{|c|}{ Disease severity rating ${ }^{z}$} \\
\hline $1 \times 10^{5}$ & 4.25 & 0 & 2.75 & 0 & 3.0 & 0 & 1.0 & 0 \\
\hline $1 \times 10^{6}$ & 4.17 & 0.50 & 4.75 & 0.25 & 4.08 & 0 & 3.33 & 0 \\
\hline $\operatorname{LSD}_{0.05}{ }^{y}$ & \multicolumn{8}{|c|}{0.76} \\
\hline
\end{tabular}

${ }^{2}$ Disease ratings were from 0 (no visible necrosis) to 5 (>80\% leaf area necrosis).

yLeast significant difference for $P \leq 0.05$.

Table 4. Dry weight per seedling of two melon cultigens of four ages, noninoculated or inoculated with two concentrations of Didymella bryoniae.

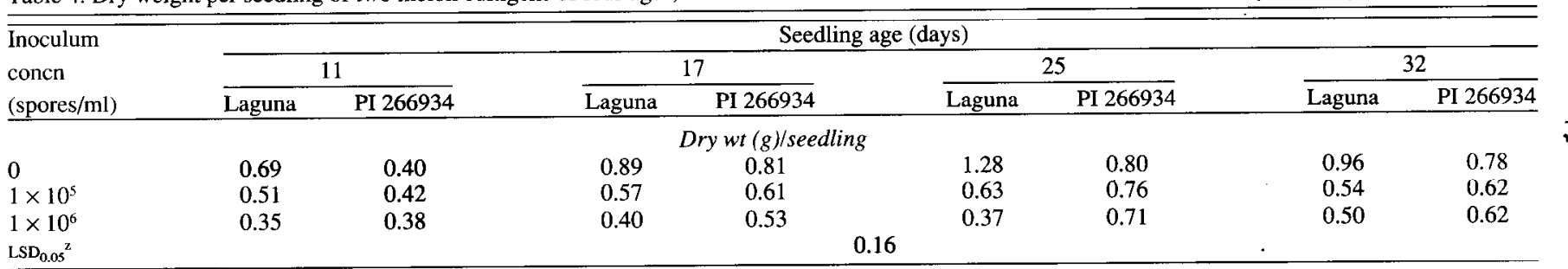

${ }^{2}$ Least significant difference for $P \leq 0.05$. 